Forum

\title{
Species-area relationships underestimate extinction rates
}

\author{
Simone Fattorini ${ }^{a, b, *}$, Paulo A.V. Borges ${ }^{a}$ \\ a Azorean Biodiversity Group (CITA-A), Departamento de Ciências Agrárias, Universidade dos Açores, Pico da Urze, $9700-042$ Angra do Heroísmo, Portugal \\ ${ }^{\mathrm{b}}$ Water Ecology Team, Department of Biotechnology and Biosciences, University of Milano Bicocca, Piazza della Scienza 2, 20126 Milan, Italy
}

\section{A R T I C L E I N F O}

\section{Article history:}

Received 26 November 2011

Accepted 21 February 2012

Available online

\section{Keywords:}

Island biogeography

Conservation biogeography

Habitat loss

Power function

SAR

Species extinction

\begin{abstract}
A B S T R A C T
The species-area relationship (SAR), i.e. the increase in species number with area, has been repeatedly used to predict species extinction, at both local and global scales, with habitat reduction. He and Hubbell (Nature, 2011; 473, 368-371), however, argued that the function that relates species loss with decreasing habitat area cannot be simply obtained reversing the species-area accumulation curve. Using a statistically more appropriate curve based on endemics (EAR), they concluded that the SAR overestimates species extinction. Although we agree that SARs and EARs have different shapes, this does not imply that SARs overestimate species extinction. Empirical evidence suggests that SARs do not overestimate, but underestimate species extinction by habitat loss and fragmentation. We discuss various examples taken from recent literature to show that SARs underestimate species extinction.
\end{abstract}

(c) 2012 Elsevier Masson SAS. All rights reserved.

\section{Introduction}

The species-area relationship (SAR), i.e. the increase in species number with area, has been repeatedly used to predict species extinction, at both local and global scales, with habitat reduction (e.g. Ney-Nifle and Mangel, 2000; Ulrich and Buszko, 2003; Triantis et al., 2010).

The SAR is typically modelled with the power function $S=C A^{z}$, where $S$ is the number of species, $A$ is area, and $C$ and $z$ are fitted parameters (Rosenzweig, 1995). Although other functions have been proposed to model the SAR, we restrict our discussion to the power-function because this is the model typically used to predict species extinction by area reduction (e.g. Reid and Miller, 1989; Wilson, 1992; Ney-Nifle and Mangel, 2000; Wilsey et al., 2005). If we suppose a reduction of area $A_{0}$ to $A_{1}$, so that the number of species $S_{0}$ is expected to decline to $S_{1}$, we obtain, after rearrangements, $S_{1}=S_{0} \times\left(A_{1} / A_{0}\right)^{z}$. The term $\left(A_{1} / A_{0}\right)^{z}$ thus represents the proportion of remaining species after area reduction. Although $z$ values show some variations according to the taxon of interest and the scale of study (i.e. some taxa respond to increasing area faster than others), in most cases it is close to $z=0.25$ and this value has been reported in most studies which used the SAR to predict

\footnotetext{
* Corresponding author. Azorean Biodiversity Group (CITA-A), Departamento de Ciências Agrárias, Universidade dos Açores, Pico da Urze, 9700-042 Angra do Heroísmo, Portugal.

E-mail address: simone_fattorini@virgilio.it (S. Fattorini).
}

species extinction (see e.g. May et al., 1995; Rosenzweig, 1995; Triantis et al., 2010).

He and Hubbell (2011) have recently identified some important theoretical flaws in the statistical assumptions on which the method is based, and claimed that the function that relates species loss with decreasing habitat area cannot be obtained simply by reversing the species-area accumulation curve. Thus, they concluded that backward SAR is an incorrect method for estimating extinction rates caused by habitat loss. In particular, using a curve based on endemics (EAR), they concluded that SARs always overestimate extinction rates from habitat loss. They based this conclusion mostly on theoretical reasoning, with a few examples from the real world (Brooks et al., 2011; Evans et al., 2011). Moreover, Kinzig and Harte (2000) have previously showed that using the appropriate endemic species-area curve, recent rates of species loss may underestimate future species extinctions under continued land clearing, but some results are controversial (see e.g. Pereira and Daily, 2006). In response to the call performed by Brooks et al. (2011), here we report several empirical evidences that SARs do not necessarily overestimate, but typically underestimate extinction rates. For this, we selected data from literature on species extinction at different scales of analyses for different contexts, and compared observed percentages of extinct species with those which can be predicted using the SAR approach. We do not propose a large review of case studies, but present an analysis of well documented cases which can be considered good examples of extinction trajectories in different communities. We do not discuss SAR applications to forecast future species extinctions at global 
scale because of large uncertainties in estimating the numbers of currently extinct species. For example, previous SAR extrapolations of species extinctions included estimates of about $15-20 \%$ of species lost between 1985 and 2000 and $25 \%$ of all species between 1985 and 2015 (e.g., World Conservation Monitoring Centre, 1992), and other cases that seem wildly exaggerated when compared with currently estimates of extinct species. However, numbers of actually extinct species which are compared with numbers extrapolated from SARs do not refer to documented extinctions, but are in turn based on extrapolations subject to high uncertainties, because of the unknown number of extinctions of undiscovered species (the so-called Linnean extinction, Riddle et al., 2011). Thus, we preferred to concentrate our discussion on local to regional studies dealing with well documented extinctions, and compare these observed values with those expected on the basis of SARs.

\section{Extinctions on islands}

As a first evidence that SARs do not overestimate extinctions, we report some analyses dealing with island biotas. Islands biotas are known to be particularly prone to species extinction, which can be really dramatic because of non-nested distributions of species. For example, single island endemics strictly associated with forest biotopes may now occur only in small forest fragments scattered across an archipelago (Triantis et al., 2010). Studies on the Azorean Islands, in which substantial areas of native vegetation were cleared for agriculture and forest monocultures in the last century, also revealed a large number of species that have not been found in the last 40 years, despite the extensive sampling effort (Triantis et al., 2010). Recent works on the Aegean Islands (a large number of islands in the Mediterranean sea) documented an impressive number of tenebrionid beetle extinctions during the 20th century (Fattorini, 2008). Important habitat loss occurred in Greece during the 20th century, especially after the 1960s (Papanastasis and Kazaklis, 1998), and the lack of records for more than 50 years can be considered strong evidence of species extinctions. Thus, we considered (locally) extinct all species not collected after 1960 from any island within the archipelago. Thus, we were able to compare the observed percentage of extinct species with those that one could estimate by a virtual dramatic reduction in suitable habitats, assuming (very conservatively) that the entire island area was initially suitable and habitat loss involved only suitable habitats. Using data on tenebrionid beetle species richness and island areas, we modelled a power function and then used the obtained $z$-value to calculate the term $\left(A_{1} / A_{0}\right)^{z}$ after a virtual reduction of original area size by $50 \%, 66.6 \%$, and $75 \%$. The best-fit SAR gave the model $S=1.547 A^{0.412}\left(R^{2}=0.660\right)$. Using $z=0.412$, when $50 \%, 63.3 \%$ and $75 \%$ of island area was virtually eliminated, the amount of remaining species was $75.2 \%, 63.7 \%$ and $56.6 \%$ respectively. In 1960 , about $73.5 \%$ of the original fauna was still present. Thus, the percentage of species extinct before 1960 is roughly the same as expected after area was virtually reduced to $50-63 \%$. In particular, an amount of remaining species of $73.5 \%$ should correspond to a virtual reduction of about $53 \%$ of island area. Similar results can be obtained using only island endemic taxa. Although important habitat loss occurred in Greece during the 20th century, such a large reduction of suitable habitat surface is obviously unrealistic and the actual extinctions are more numerous than would be expected using the SAR.

\section{Extinction by urbanization}

As a second example, we used data from a long-term study (Fattorini, 2011) in urban Rome $\left(360 \mathrm{~km}^{2}\right)$, one of the most ancient cities in the world. This study revealed high percentages of species extinction in different insect groups. From 1880 to 1999, extinct species were: $65 \%$ in coprophagous scarabaeids (from 89 to 31 species), $56 \%$ in non-coprophagous scarabaeids (from 39 to 17 species), $32 \%$ in tenebrionids (from 37 to 25 species), and $45 \%$ in butterflies (from 60 to 33 species) (introduced and anthropophilous species excluded). In this period, the percentage of built-up surface within the study area increased from about $14 \mathrm{~km}^{2}(1.25 \%)$ to about $180 \mathrm{~km}^{2}$ (50\%). Using the SAR with a conventional $z=0.25$, we would expect $16 \%$ of extinct species in each group. This estimate is largely lower than the observed percentages. Moreover, 0.25 for the $z$ parameter is a very high value, typically found in true isolates, such as islands, whereas mainland systems tend to have lower values, which would predict even lower extinction rates. To match the observed extinction rates, $z$-values should range between about 0.5 and 1.5 , which are unrealistic values for the SAR. Values of $z$ close to 1 seem to be only possible for interprovincial species-area relationships (e.g. using single-island endemics) (Triantis et al., 2008).

\section{Extinction by regional land use changes}

As an example of extinctions determined by regional changes in land use, we considered a European scenario (Maes and Van Dyck, 2001). Extinction trends are well documented in northwest Europe, and data for butterflies in north Belgium (Flanders) are available since 1830 . During the 20th century about 30\% of butterflies became extinct because of large scale changes in land use. In particular, natural and semi-natural habitats in Flanders declined to $61 \%$. Using this proportion, a SAR with $z=0.25$ would predict only about $12 \%$ of extinct species, and even fewer extinctions would be predicted using lower $z$-values as commonly found in mainland SARs. Again, to match the observed extinction rates, $z$-values should have a very high value, close to 1 .

\section{Extinction by deforestation}

Because SARs have been especially used to predict species extinctions in tropical forest habitats, we finally considered two examples of extinctions by deforestation. In general, it is difficult to evaluate extinction rates in forest ecosystems because of the large number of still undescribed species and the lack of adequate information on extinctions. Thus, we selected two examples reporting well documented extinctions in well known taxa/areas. Forest losses and bird extinctions in North America are well documented (Pimm and Askins, 1995). Forest clearing in North America reached a peak in 1872 , when only half of the area covered by the eastern forest at the time of European settlement (1620) was still wooded (after 1920, the amount of deciduous forest showed a steady increase in the Northeast and the South). The $z$-values typically observed for continental sample areas fall between 0.1 and 0.2 (Rosenzweig, 1995). With a $50 \%$ loss of habitat, a value of $z=0.15$ predicts a $10 \%$ loss of species. Out of the 28 species of birds restricted to the North American forest habitat, 4 have gone extinct (Pimm and Askins, 1995), which means a 14\% loss of species. Madagascar, one of the most important biodiversity hotspots at global scale, has lost about half of its forest cover since 1953. Extensive sampling of endemic forest dwelling Helictopleurini dung beetles (Hanski et al., 2007), revealed that 22 out of 51 previously known species were probably extinct (43\%), a percentage much larger than that predicted from the fitted SAR (10-16\% for $z$-values ranging from 0.15 to 0.25 ).

\section{Conclusions}

The primary driver of current decreases in population densities and species losses is habitat extirpation. The examples presented in 
this contribution indicate that, contrary to He and Hubbell's conclusions, SARs do not overestimate, but may underestimate extinction rates. Our empirical examples will not prove an obligatory underestimation, and we cannot exclude that SARs can overestimate species extinctions. However, we believe that these examples are representative of widespread circumstances in which SARs will underestimate species extinctions.

One could argue that our examples are incorrect because the extinctions described in the cited cases are real but are not solely caused by habitat loss, whereas the interpretation of He and Hubbell's results must be strictly applied to the use of the backward SAR to habitat destruction. As a result, SAR-based models would be hardly appropriate for modelling the extinction rates discussed here. This criticism might be applied to some of our examples, but cannot evoked for those regarding the extinctions due to deforestation, because they were based on forest specialist species whose extinction is attributed to deforestation, and thus fall within the usual application of SAR to predict extinctions.

We admit that the extinctions discussed here may involve factors different from habitat reduction. However, if habitat reduction is not the primary cause of extinction, then the use of SARs to forecast species extinctions is inappropriate because it assumes that habitat reduction is the main cause of species extinction (Triantis and Bhagwat, 2011). Although many reasons may be evoked to explain why species extinction proceeds faster than predicted by reduction in habitat area (such as pollution, global climatic changes, overexploitation, introduction of exotics, matrix and edge effects, or diseases), habitat fragmentation is typically recognised as a major driver of extinction (Laurance, 2008; Lomolino et al., 2010). Habitat fragmentation causes not only habitat loss/reduction, but also promotes habitat isolation, diminishes habitat quality, and increases edge effects (Fischer and Lindenmayer, 2007). In addition, habitat fragmentation promotes the spread of exotic species (Borges et al., 2006), and changes the relative abundances of trophic groups, deeply affecting trophic structure, food web structure and ecosystem functions (Didham et al., 1998). In general, a single continuous area hosts more species than a number of fragments of the same total surface (Lomolino et al., 2010). One of the best documented examples of local extinction of multiple species because of habitat fragmentation is the loss of bird species from Barro Colorado Island in Panama. Before the construction of Panama Canal, the island was simply a hill in a sector of tropical lowland forest. In1914, when the Chagras River was dammed and the rising waters of Gatun lake covered the adjacent lowland areas, this sector of lowland forest abruptly became an island. Comparing the avifauna of the island with that of a mainland site of similar size and habitat, it has been concluded that at least 65 species (about 30\% of the 220 resident breeding species surveyed over 85 years of research) have become extinct on this island since its isolation (Willis, 1974; Robinson, 1999).

Island biotas, which are intrinsically fragmented and occupy reduced areas, are particularly prone to habitat fragmentation, and this may be an explanation for the very high number of tenebrionid extinctions recorded on the Aegean Islands (Fattorini, 2008) and the extinction debt predicted for the Azores (Triantis et al., 2010). In the Azorean Islands, we were able to apply an index of Biotic Integrity based on several metrics of arthropod abundance and richness, showing that continuous areas of native forest have higher biodiversity values than highly fragmented areas, which in contrast show a community disharmony, with a hyperabundance of exotic and generalist species (Gaspar et al., 2011). For urban Rome, fragmentation of natural habitats is impressive (current green spaces are fragmented into more than twenty protected areas) (Fattorini, 2011). Habitat fragmentation is also recognised as the major factor responsible for butterfly extinction in Flanders (Maes and Van Dyck, 2001). Because SARs consider only total surface, without regard for the fact it is continuous or fragmented, they can hardly provide realistic estimates of species loss. Moreover, SARs (and EARs) consider only species numbers, not number of individuals and species identity. This means that species might be considered as 'present' even if their numbers are below the minimum viable population (Babu, 2011). Attempts to apply the SAR model without considering fragmentation may underestimate the nonrandom factors that shape communities in habitat remnants. Thus, He and Hubbell's optimistic view that global species extinction proceeds more slowly than assumed by SAR estimates is unfortunately not supported by the real world.

\section{Acknowledgements}

We are grateful to Juan Morrone, Bram Vanschoenwinkel, and an anonymous referee for their comments on a previous version of this paper.

\section{References}

Babu, S., 2011. Comment \#21938. Nature. http://www.nature.com/nature/journal/ v473/n7347/full/nature09985.html\#/comments.

Borges, P.A.V., Lobo, J.M., Azevedo, E.B., Gaspar, C., Melo, C., Nunes, L.V., 2006. Invasibility and species richness of island endemic arthropods: a general model of endemic vs. exotic species. J. Biogreogr. 33, 169-187.

Brooks, T.M., Brook, B.W., Koh, L.P., Pereira, H.M., Pimm, S.L., Rosenzweig, M.L., Sodhi, N.S., 2011. Extinctions: consider all species. Nature 474, 284.

Didham, R.K., Lawton, J.H., Hammond, P.M., Eggleton, P., 1998. Trophic structure stability and extinction dynamics of beetles (Coleoptera) in tropical forest fragments. Phil. Trans. R. Soc. Lond. B 353, 437-451.

Evans, M., Possingham, H., Wilson, K., 2011. Extinctions: conserve not collate. Nature 474, 284.

Fattorini, S., 2008. A multidimensional characterization of rarity applied to the Aegean tenebrionid beetles (Coleoptera Tenebrionidae). J. Insect Conserv. 12, 251-263.

Fattorini, S., 2011. Insect extinction by urbanization: a long term study in Rome. Biol. Conserv. 144, 370-375.

Fischer, J., Lindenmayer, D.B., 2007. Landscape modification and habitat fragmentation: a synthesis. Glob. Ecol. Biogeogr. 16, 265-280.

Gaspar, C., Gaston, K.J., Borges, P.A.V., Cardoso, P., 2011. Selection of priority areas for arthropod conservation in the Azores archipelago. J. Insect Conserv. 15, 671-684.

Hanski, I., Koivulehto, H., Cameron, A., Rahagalala, P., 2007. Deforestation and apparent extinctions of endemic forest beetles in Madagascar. Biol. Lett. 3, 344-347.

He, F.T., Hubbell, S.P., 2011. Species-area relationships always overestimate extinction rates from habitat loss. Nature 473, 368-371.

Kinzig, A.P., Harte, J., 2000. Implications of endemics-area relationships for estimates of species extinctions. Ecology 81, 3305-3311.

Laurance, W.F., 2008. Theory meets reality: how habitat fragmentation research has transcended island biogeographic theory. Biol. Conserv. 141, 1731-1744.

Lomolino, M.V., Riddle, B.R., Whittaker, R.J., Brown, J.H., 2010. Biogeography, fourth ed. Sinauer Associates, Sunderland.

Maes, D., Van Dyck, H., 2001. Butterfly diversity loss in Flanders (north Belgium): Europe's worst case scenario? Biol. Conserv 99, 263-276.

May, R.M., Lawton, J.H., Stork, N.E., 1995. Assessing extinction rates. In: Lawton, J.H., May, R.M. (Eds.), Extinction Rates. Oxford University Press, Oxford, pp. 1-24.

Ney-Nifle, M., Mangel, M., 2000. Habitat loss and changes in the species-area relationship. Conserv. Biol. 14, 893-898.

Papanastasis, V.P., Kazaklis, A., 1998. Land use changes and conflicts in the Mediterranean-type ecosystems of Western Crete. In: Rundel, P.W., Montenegro, G., Jaksic, F.M. (Eds.), Landscape Disturbance and Biodiversity in Mediterranean-Type Ecosystems. Springer-Verlag, Berlin, pp. 141-154.

Pereira, H.M., Daily, G.C., 2006. Modeling biodiversity dynamics in countryside landscapes. Ecology 87, 1877-1885.

Pimm, S.L., Askins, R.A., 1995. Forest losses predict bird extinctions in eastern North America. Proc. Natl. Acad. Sci. U.S.A. 92, 9343-9347.

Reid, W.V., Miller, K.R., 1989. Keeping Options Alive: The Scientific Basis for Conserving Biodiversity. World Resources Institute, Washington.

Riddle, B.R., Ladle, R.J., Lourie, S.A., Whittaker, R.J., 2011. Basic biogeography: estimating biodiversity and mapping nature. In: Ladle, R.J., Whittaker, R.J. (Eds.), Conservation Biogeography. Wiley-Blackwell, Chichester, pp. 47-92.

Robinson, W.D., 1999. Long-term changes in the avifauna of Barro Colorado Island, Panama, a tropical forest isolate. Conserv. Biol. 13, 85-97.

Rosenzweig, M.L., 1995. Species Diversity in Space and Time. Cambridge University Press, Cambridge. 
Triantis, K.A., Bhagwat, S.A., 2011. Applied island biogeography. In: Ladle, R.J., Whittaker, R.J. (Eds.), Conservation Biogeography. Wiley-Blackwell, Chichester, pp. 190-223.

Triantis, K.A., Borges, P.A.V., Ladle, R.J., Hortal, J., Cardoso, P., Gaspar, C., Dinis, F., Mendonça, E., Silveira, L.M.A., Gabriel, R., Melo, C., Santos, A.M.C., Amorim, I.R. Ribeiro, S.P., Serrano, A.R.M., Quartau, J.A., Whittaker, R.J., 2010. Extinction debt on oceanic islands. Ecography 33, 285-294.

Triantis, K.A., Mylonas, M., Whittaker, R.J., 2008. Evolutionary species-area curves as revealed by single-island endemics: insights for the interprovincial species-area relationship. Ecography 31, 401-407.
Ulrich, W., Buszko, J., 2003. Species-area relationships of butterflies in Europe and species richness forecasting. Ecography 26, 365-373.

Willis, E.O., 1974. Populations and local extinctions of birds on Barro Colorado island, Panama. Ecol. Mon. 44, 153-169.

Wilsey, B.J., Martin, L.M., Polley, H.W., 2005. Predicting plant extinction based on species-area curves in prairie fragments with high beta richness. Conserv. Biol. 19, 1835-1841.

Wilson, E.O., 1992. The Diversity of Life. Belknap Press, Cambridge, MA.

World Conservation Monitoring Centre, 1992. Global Biodiversity: Status of the Earth's Living Resources. Chapman and Hall, London. 